\title{
PENGARUH BUDAYA KERJA, PEMBERDAYAAN DAN SIKAP KERJA TERHADAP KINERJA PEGAWAI DI BADAN KEPEGAWAIAN DAERAH KABUPATEN LABUHANBATU SELATAN
}

\author{
${ }^{1}$ Rizki Zenia, ${ }^{2}$ Nazamuddin, ${ }^{3}$ Dimaswari Sefrizal, ${ }^{4}$ Santi Akusti, ${ }^{5}$ Sarimin \\ 1,2,3,4,5 Universitas Islam Sumatera Utara \\ rizki.zenia@gmail.com, ${ }^{2}$ nazamuddin.mm@gmail.com, ${ }^{3}$ dimaswari.sefrizal@ gmail.com, ${ }^{4}$ santi.akusti@gmail.com, \\ sarimin.mm@gmail.com
}

\begin{abstract}
Problem of this study how influence of job culture on performance. How influence of empowerment on performance. How influence of work attitude on performance. How influence job culture, empowerment and work attitude on performance. The purpose of this study to determine and analyze the effect of job culture on performance. Determine and analyze the effect of empowerment on performance. Determine and analyze the effect of work attitude on performance. Determine and analyze the effect of job culture, empowerment and work attitude on performance. Sample in the study is 34 employees. Data analysis techniques used in this study is descriptive analyze and multiple linear regression analysis. The results of the study indicate job culture variable has a positive and significant effect on performance. empowerment variable has a positive and significant effect on performance. work attitude variable has a positive and significant effect on performance. Job culture, empowerment and work attitude variable has a positive and significant effect on performance.
\end{abstract}

Keywords : Job culture, Empowerment, Work attitude, Performance.

ABSTRAK : Rumusan masalah dalam penelitian ini adalah apakah ada pengaruh budaya kerja terhadap kinerja. Apakah ada pengaruh pemberdayaan terhadap kinerja. Apakah ada pengaruh sikap kerja terhadap kinerja. Apakah ada pengaruh budaya kerja, pemberdayaan dan sikap kerja terhadap kinerja. Tujuan penelitian ini adalah untuk mengetahui dan menganalisis pengaruh budaya kerja terhadap kinerja. Untuk mengetahui dan menganalisis pengaruh pemberdayaan terhadap kinerja. Untuk mengetahui dan menganalisis pengaruh sikap kerja terhadap kinerja. Untuk mengetahui dan menganalisis pengaruh budaya kerja, pemberdayaan dan sikap kerja terhadap kinerja. Sampel dalam penelitian ini berjumlah 34 orang pegawai. Teknik analisis data yang digunakan dalam penelitian ini adalah analisis deskriptif dan analisis regresi linier berganda. Hasil penelitian ini menjelaskan bahwa variabel budaya kerja berpengaruh positif dan signifikan terhadap kinerja. Variabel pemberdayaan berpengaruh positif dan signifikan terhadap kinerja. Variabel sikap kerja berpengaruh positif dan signifikan terhadap kinerja. Variabel budaya kerja, pemberdayaan, dan sikap kerja berpengaruh positif dan signifikan terhadap kinerja .

Kata kunci : Budaya kerja, Pemberdayaan, Sikap kerja, Kinerja

\section{Pendahuluan}

Pada dasarnya Pembangunan Daerah adalah merupakan sub sistem dari rangkaian pelaksanaan pembangunan Nasional, yang dilakukan oleh masyarakat bersama dengan Pemerintah di daerah secara berencana, bertahap dan berkesinambungan sesuai dengan kondisi dan potensi yang timbul dan berkembang di daerahnya.

Badan Kepegawaian Daerah kabupaten Labuhanbatu Selatan mempunyai tugas melaksanakan urusan pemerintahan daerah di bidang kepegawaian, pengembangan, data dan kesejahteraan, mutasi, pendidikan dan pelatihan dan pembinaan aparatur yang dalam mendukung pembangunan daerah dan pembangunan nasional pada penyelenggaraan Pemerintahan Kabupaten Labuhanbatu Selatan. Dalam hal pencapaian hasil yang optimal dalam melaksanakan tugas pokok tersebut, perlu disusun suatu perencanaan strategik yang meliputi keseluruhan pembagian tugas dari 
masing-masing bidang di lingkungan Badan Kepegawaian Daerah Kabupaten Labuhanbatu Selatan, guna dijadikan sebagai pedoman dan arahan dalam melaksanakan tugas dan fungsinya dalam mewujudkan visi, misi dan tujuan Badan Kepegawaian Daerah Kabupaten Labuhanbatu Selatan yang akan dicapai, sekaligus untuk dijadikan tolok ukur dalam melakukan evaluasi kinerja setiap tahunnya.

Guna mewujudkan tugas dan fungsinya Badan Kepegawaian Daerah Kabupaten Labuhanbatu Selatan harus mempunyai sumber daya manusia (pegawai) dengan kinerja yang baik. Dimana kinerja merupakan akumulasi hasil akhir dari semua kegiatan seseorang yang ada di organisasi. Kegiatan tersebut bisa berupa tercapainya target kerja yang diemban dalam satu periode, atau dapat pula mengemban tanggungjawab pekerjaan seefisien dan seefektif mungkin. Untuk mengungkap permasalah tentang kinerja pegawai, peneliti melakukan wawancara dengan Kepala Badan Kepegawaian Daerah Kabupaten Labuhanbatu Selatan. Dari hasil wawancara tersebut dapat ditarik kesimpulan bahwa hasil kerja pegawai baik ditinjau dari sisi kualitas dan kuantitas hasil kerja masih perlu perhatian, karena masih ada proses pelayanan administrasi yang terkesan masih lamban karena adanya birokrasi dan kemampuan pegawai yang belum optimal.

Untuk mengatasi permasalahan tersebut, maka Badan Kepegawaian Daerah Kabupaten Labuhanbatu Selatan perlu mengatasinya dengan cara memberdayakan kemampuan pegawai seoptimal mungkin sehingga hasil kerja yang diharapkan dapat tercapai. Pemberdayaan dianggap mampu menumbuhkan dan meningkatkan kreativitas para pegawai. Dimana kreativitas merupakan landasan bagi tumbuh berkembangnya inovasi. Pegawai yang memiliki kreativitas akan selalu mencari cara atau metode baru yang tepat dalam upaya untuk menghasilkan suatu hasil kerja yang berkualitas. Pegawai yang kreatif juga memberikan andil yang besar bagi terciptanya inovasi kerja. Oleh karena itu, pemberdayaan dipandang menjadi bagian yang penting dalam rangka menjamin kelangsungan hidup organisasi dalam lingkungan yang kompetitif. Pemberdayaan di Badan Kepegawaian Daerah Kabupaten Labuhanbatu Selatan difokuskan pada penyediaan jasa pelayanan dari pegawai. Melalui konsep ini, pegawai diharapkan mempunyai wewenang dan tanggung jawab yang lebih besar dalam mengambil keputusan.
Untuk itu dibutuhkan komunikasi atau saling tukar menukar informasi dan pengetahuan antara atasan dan bawahan sehingga para pegawai dapat benar-benar memahami tugasnya dan dapat memberikan kontribusi yang nyata pada pencapaian kinerja organisasi. Hasil penelitian dari Arifudin et.al (2018) menarik kesimpulan bahwa pemberdayaan berpengaruh negatif dan tidak signifikan terhadap kinerja. Sementara hasil penelitian dari I Putu Magna Anuraga et.al (2017), dan Hasan Tutar et.al (2011) menarik kesimpulan bahwa pemberdayaan berpengaruh positif dan signifikan terhadap kinerja. Dari penelitian terdahulu tersebut masih terdapat hasil yang tidak konsisten sehingga peneliti tertarik melakukan penelitian lanjutan terhadap pegawai di Badan Kepegawaian Daerah Kabupaten Labuhanbatu Selatan.

Sikap kerja sehari-hari dalam bekerja juga dapat mempengaruhi kinerja pegawai di Badan Kepegawaian Daerah Kabupaten Labuhanbatu Selatan. Sikap merupakan kecenderungan merespon sesuatu secara konsisten untuk mendukung atau tidak mendukung dengan memperhatikan objek tertentu. Sehingga pegawai yang memiliki sikap kerja tinggi maka akan memiliki kemampuan kinerja pegawai secara rasional tinggi pula, sebaliknya pegawai yang memiliki sikap kerja negatif maka kinerja pegawai secara rasional rendah. Hasil penelitian terdahulu dari Chres F.P Laoh et.al (2016), Famella et.al (2015), Fonny Corryda Rahayu (2013), dan Alias et.al (2018), kesemuanya menarik kesimpulan sikap kerja berpengaruh positif dan signifikan terhadap kinerja. Sementara hasil penelitian terdahulu dari Rd. Kresna et.al (2017), menarik kesimpulan sikap kerja berpengaruh negatif dan tidak signifikan terhadap kinerja. Tidak konsistennya dari penelitian terdahulu tersebut sehingga peneliti tertarik melakukan penelitian lanjutan terhadap pegawai di Badan Kepegawaian Daerah Kabupaten Labuhanbatu Selatan.

Selain program pemberdayaan dan sikap kerja, maka faktor budaya kerja juga penting dalam meningkatkan kinerja pegawai di Badan Kepegawaian Daerah Kabupaten Labuhanbatu Selatan. Budaya kerja merupakan cara pandang seseorang dalam memberi makna terhadap kerja. Dengan demikian, budaya kerja merupakan cara pandang seseorang terhadap bidang yang ditekuninya dan prinsip-prinsip moral yang dimiliki, yang menumbuhkan keyakinan yang kuat atas dasar nilai-nilai yang 
diyakini, memiliki semangat yang tinggi dan bersungguh-sungguh untuk mewujudkan prestasi terbaik. Budaya kerja adalah berpijak dari nilai-nilai yang dimiliki oleh bangsa atau masyarakat Indonesia yang diolah sedemikian rupa menjadi nilai-nilai baru yang akan menjadi sikap dan perilaku manajemen yang diharapkan dalam upaya menghadapi tantangan baru. Budaya kerja tidak akan muncul begitu saja, akan tetapi harus diupayakan dengan sungguhsungguh melalui proses yang terkendali dengan melibatkan semua sumber daya manusia dalam seperangkat sistem, alat-alat dan teknik-teknik pendukung. Hasil penelitian terdahulu yang relevan dengan penelitian ini, diantaranya penelitian yang dilakukan oleh Hakim (2015), dan Alia et.al (2015), menunjukkan bahwa budaya kerja berpengaruh positif dan signifikan terhadap kinerja. Hasil penelitian yang relevan dilakukan oleh Artina et.al (2014), menyatakan dalam hasil penelitiannya bahwa budaya kerja berpengaruh negatif dan tidak signifikan terhadap kinerja. Berdasarkan riset gap tersebut, maka perlu diuji kembali secara empirik pengaruh budaya kerja terhadap kinerja pegawai di Badan Kepegawaian Daerah Kabupaten Labuhanbatu Selatan.

\subsection{Rumusan Masalah}

Berdasarkan batasan masalah yang telah diidentifikasi maka peneliti merumuskan masalah yang berkaitan dengan penelitian ini adalah :

1) Apakah ada pengaruh budaya kerja terhadap kinerja pegawai di Badan Kepegawaian Daerah Kabupaten Labuhanbatu Selatan.

2) Apakah ada pengaruh pemberdayaan terhadap kinerja pegawai di Badan Kepegawaian Daerah Kabupaten Labuhanbatu Selatan.

3) Apakah ada pengaruh sikap kerja terhadap kinerja pegawai di Badan Kepegawaian Daerah Kabupaten Labuhanbatu Selatan

4) Apakah ada pengaruh budaya kerja, pemberdayaan dan sikap kerja terhadap kinerja pegawai di Badan Kepegawaian Daerah Kabupaten Labuhanbatu Selatan.

\subsection{Batasan Masalah}

Berdasarkan uraian di atas, banyak faktor yang berpengaruh pada variabel kinerja pegawai di Badan Kepegawaian Daerah Kabupaten Labuhanbatu Selatan, sehingga dalam penelitian ini peneliti membatasi kepada variabel independen yaitu budaya kerja, pemberdayaan dan sikap kerja.

\subsection{Hipotesis}

Berdasarkan pada kerangka konseptual di atas, maka hipotesis dalam penelitian ini adalah :

1. Ada pengaruh budaya kerja terhadap kinerja pegawai di Badan Kepegawaian Daerah Kabupaten Labuhanbatu Selatan.

2. Ada pengaruh pemberdayaan terhadap kinerja pegawai di Badan Kepegawaian Daerah Kabupaten Labuhanbatu Selatan.

3. Ada pengaruh sikap kerja terhadap kinerja pegawai di Badan Kepegawaian Daerah Kabupaten Labuhanbatu Selatan.

4. Ada pengaruh budaya kerja, pemberdayaan dan sikap kerja terhadap kinerja pegawai di Badan Kepegawaian Daerah Kabupaten Labuhanbatu Selatan.

\subsection{Tujuan Penelitian}

Tujuan dari penelitian ini adalah :

1) Untuk menganalisis pengaruh budaya kerja terhadap kinerja pegawai di Badan Kepegawaian Daerah Kabupaten Labuhanbatu Selatan.

2) Untuk menganalisis pengaruh pemberdayaan terhadap kinerja pegawai di Badan Kepegawaian Daerah Kabupaten Labuhanbatu Selatan.

3) Untuk menganalisis pengaruh sikap kerja terhadap kinerja pegawai di Badan Kepegawaian Daerah Kabupaten Labuhanbatu Selatan

4) Untuk menganalisis pengaruh budaya kerja, pemberdayaan dan sikap kerja terhadap kinerja pegawai di Badan Kepegawaian Daerah Kabupaten Labuhanbatu Selatan.

\section{Metode Penelitian \\ 2.1. Populasi}

Menurut Sugiyono (2014:55), populasi adalah wilayah generalisasi yang terdiri atas obyek/subjek yang mempunyai kuantitas dan karakteristik tertentu yang ditetapkan oleh peneliti untuk dipelajari dan kemudian ditarik kesimpulannya. Jadi populasi bukan hanya orang tetapi juga benda-benda alam yang lain. Populasi juga bukan sekedar jumlah yang ada pada objek/subjek yang dipelajari, tetapi meliputi seluruh karakteristik, sifat yang dimiliki objek/subjek itu. Dari pengertian tersebut, maka dapat disimpulkan bahwa 
populasi merupakan subjek penelitian dimana individu yang akan dikenai perilaku atau dapat dikatakan sebagai keseluruhan objek penelitian yang akan diteliti. Maka populasi dalam penelitian ini adalah para pegawai Badan
Kepegawaian Daerah Kabupaten Labuhanbatu Selatan yang berjumlah 34 orang. dimana Kepala Badan dan peneliti tidak dihitung sebagai populasi.

Tabel 1. Kerangka populasi pegawai

\begin{tabular}{|c|l|c|}
\hline No & \multicolumn{1}{|c|}{ Keterangan } & Jumlah (Orang) \\
\hline 1 & Sekretariat & 10 \\
\hline 2 & Bidang Program Pendataan Kepegawaian & 8 \\
\hline 3 & Bidang Mutasi & 9 \\
\hline 4 & Bidang Pengembangan dan Pemberdayaan Pegawai & 7 \\
\hline \multicolumn{2}{|c|}{ Jumlah } & 34 \\
\hline
\end{tabular}

Sumber : BKD Kabupaten Labusel, 2021

\subsection{Sampel}

Menurut Sugiyono (2011:93), sampel adalah elemen-elemen populasi yang dipilih atas dasar kemampuan mewakilinya. Untuk menjadi pedoman jika subjeknya atau populasinya kurang dari 100, maka lebih baik diambil semua sebagai sampel, sehingga penelitiannya merupakan penelitian populasi.
Selanjutnya jika jumlah subjeknya atau populasinya besar atau lebih dari 100, maka dapat diambil persentasenya. Dengan menggunakan teknik penarikan sampel yaitu total sampling atau metode sensus, maka sampel dalam penelitian ini berjumlah 34 orang pegawai di Badan Kepegawaian Daerah Kabupaten Labuhanbatu Selatan.

Tabel 2. Kerangka sampel pegawai

\begin{tabular}{|c|l|c|}
\hline No & \multicolumn{1}{|c|}{ Keterangan } & Jumlah (Orang) \\
\hline 1 & Sekretariat & 10 \\
\hline 2 & Bidang Program Pendataan Kepegawaian & 8 \\
\hline 3 & Bidang Mutasi & 9 \\
\hline 4 & Bidang Pengembangan dan Pemberdayaan Pegawai & 7 \\
\hline \multicolumn{2}{|c|}{ Jumlah } & 34 \\
\hline
\end{tabular}

Sumber : BKD Kabupaten Labusel, 2021

\subsection{Uji Normalitas}

Distribusi normal akan membentuk satu garis lurus diagonal dan ploating data residual akan dibandingkan dengan garis diagonal. Jika distribusi atau residual normal, maka garis yang menggambarkan data yang sesungguhnya akan mengikuti garis diagonalnya. Uji normalitas dengan grafik dapat dilakukan dengan program SPSS dengan analisis grafik Normal Probability Plot

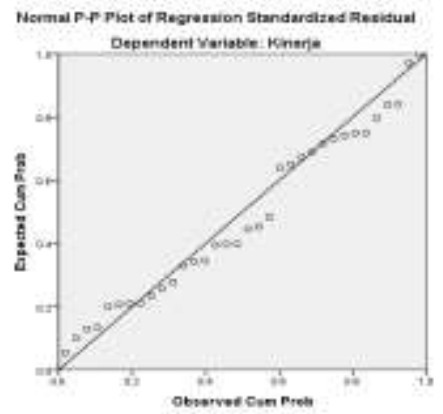

Gambar 1. Uji normalitas data

Berdasarkan gambar 1. diatas terlihat titiktitik dari ploating data residual berada di garis diagonal, hal ini dapat disimpulkan data yang diuji berdistribusi normal.

\subsection{Uji Multikolinieritas}

Salah satu asumsi dari model regresi linier bahwa tidak terjadi korelasi yang signifikan antara variabel bebasnya. Untuk menguji hal tersebut maka diperlukan suatu uji yang disebut uji multikolinieritas. Menurut Duwi Priyatno (2012:151) pengertian multikolinieritas adalah keadaan di mana pada model regresi ditemukan adanya korelasi yang sempurna atau mendekati sempurna antar variabel independen. Pada regresi yang baik seharusnya tidak terjadi korelasi yang sempurna atau mendekati sempurna diantara variabel bebas. Uji multikolinieritas adalah untuk melihat ada atau tidaknya korelasi yang tinggi antara variabelvariabel bebasnya, maka hubungan antara variabel bebas terhadap variabel terikatnya menjadi terganggu. Jika terdapat korelasi yang kuat dimana sesama variabel independen maka konsekuensinya adalah : 
a. Koefisien-koefisien regresi menjadi tidak dapat ditaksir

b. Nilai standar error setiap koefisien regresi menjadi tidak terhingga.

Dengan demikian, semakin besar korelasi diantara sesama variabel independen maka tingkat kesalahan dari koefisien regresi semakin besar yang dapat mengakibatkan standar error semakin besar pula. Cara yang digunakan untuk mendeteksi ada tidaknya multikolinieritas adalah dengan melihat besarnya nilai Variance Inflation Factor (VIF). Jika VIF dibawah 10 dan Tolerance Value diatas 0,1 maka tidak terjadi multikolinieritas.

Tabel 3. Uji multikolinieritas

\begin{tabular}{|l|c|c|}
\hline \multirow{2}{*}{\multicolumn{1}{|c|}{ Variabel }} & \multicolumn{2}{c|}{ Collinearity Statistics } \\
\cline { 2 - 3 } & Tolerance & VIF \\
\hline Budaya kerja & 0.902 & 1.108 \\
\hline Pemberdayaan & 0.986 & 1.014 \\
\hline Sikap kerja & 0.910 & 1.099 \\
\hline
\end{tabular}

a. Dependent Variable : Kinerja

Hasil pengolahan data, 2021

Berdasarkan Tabel 3 diatas diperoleh nilai Tolerance Value diatas 0.1 yaitu 0.902, 0.986, dan 0.910 , hal ini menunjukan adanya korelasi yang cukup tinggi/kuat antara sesama variabel bebas dan nilai Variance Inflantion Factorrs (VIF) sebesar 1.108, 1.014, dan 1.099, dimana nilai VIF dari ketiga varibel bebas lebih kecil dari 10 dan dapat disimpulkan tidak terdapat multikolinieritas diantara ketiga variabel bebas yang diuji dalam penelitian ini.

\subsection{Uji Autokorelasi}

Uji autokorelasi merupakan pengujian dimana variabel dependen tidak berkorelasi dengan nilai variabel itu sendiri, baik nilai periode sebelumnya maupun nilai periode sesudahnya. Menurut Duwi Priyatno
(2012:172) pengertian dari autokorelasi adalah keadaan di mana pada model regresi ada korelasi antara residual pada periode tertentu $\mathrm{t}$ dengan residual pada periode sebelumnya ( $\mathrm{t}-1)$, model regresi yang baik adalah yang tidak terdapat masalah autokorelasi. Metode pengujian menggunakan uji Durbin-Watson (DW-test). Salah satu ukuran dalam menentukan ada tidaknya masalah autokorelasi dengan uji Durbin-Watson (DW) dengan ketentuan sebagai berikut :

Terjadi autokorelasi positif jika nilai DW dibawah -2 atau DW $<-2$

Tidak terjadi autokorelasi jika nilai DW diantara -2 dan +2 atau $-2<\mathrm{DW}<+2$

Terjadi autokorelasi negatif jika nilai DW di atas 2 atau DW $>2$.

Tabel 4. Uji Autokorelasi

\begin{tabular}{|c|c|c|c|c|c|c|}
\hline \multirow[b]{2}{*}{ Model } & \multicolumn{5}{|c|}{ Change Statistics } & \multirow{2}{*}{$\begin{array}{l}\text { Durbin- } \\
\text { Watson }\end{array}$} \\
\hline & $\begin{array}{c}R \text { Square } \\
\text { Change }\end{array}$ & F Change & df1 & df2 & $\begin{array}{c}\text { Sig. F } \\
\text { Change }\end{array}$ & \\
\hline 1 & .608 & 15.511 & 3 & 30 & .000 & 2.136 \\
\hline
\end{tabular}

Hasil pengolahan data, 2021

Berdasarkan Tabel 4 di atas diperoleh nilai Durbin-Watson (DW) sebesar 2.136, nilai ini berada pada kisaran $-2<\mathrm{DW}<+2$, maka dapat disimpulkan bahwa tidak terjadi autokorelasi pada model regresi dalam penelitian ini.

\subsection{Uji Heteroskedastisitas}

Uji heteroskedastisitas bertujuan untuk menguji apakah dalam model regresi terjadi ketidaksamaan variance dari residual satu pengamatan ke pengamatan yang lainnya. Gejala variance yang tidak sama ini disebut dengan heteroskedastisitas, sedangkan adanya gejala residual yang sama dari satu pengamatan ke pengamatan lain disebut dengan homokedastisitas. Menurut Duwi Priyatno (2012:158) pengertian dari heteroskedastisitas adalah dimana dalam model regresi tejadi ketidaksamaan varian dari residual pada suatu pengamatan ke pengamatan yang lain. Model regresi yang baik adalah tidak terjadi heteroskedastisitas. Berbagai macam uji heteroskedastisitas yaitu dengan uji glejser, melihat pola titik-titik pada scatterplots regresi, atau uji koefisien korelasi spearman's.

Uji heteroskedastisitas dapat dilakukan dengan menggunakan grafik scatterplot antara nilai variabel terikat (ZSPRED) dengan 
residualnya (SRESID), dimana sumbu $X$ adalah yang diprediksi dan sumbu $\mathrm{Y}$ adalah residual. Dasar pengambilan keputusan yang dapat diambil adalah sebagai berikut :

a. Jika pola tertentu seperti titik-titik yang ada membentuk suatu pola yang teratur (bergelombang, melebar kemudian menyempit) maka telah terjadi heteroskedastisitas.

b. Jika tidak ada yang jelas serta titik-titik menyebar diatas dan dibawah angka nol pada sumbu $\mathrm{Y}$ maka tidak terjadi heteroskedastisitas

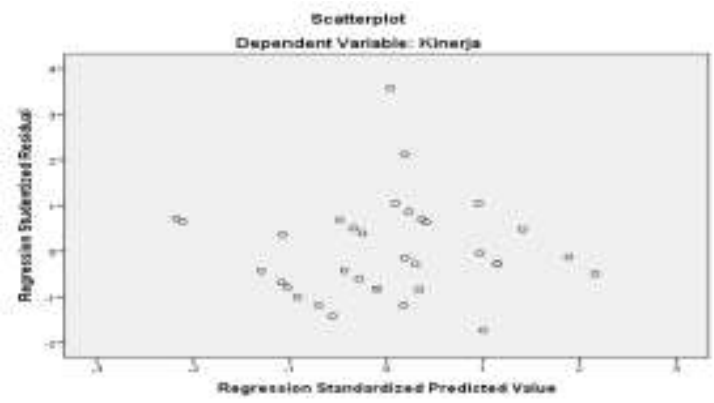

Berdasarkan gambar 2, diatas, menunjukkan titik-titik yang menyebar, sehingga dapat disimpulkan tidak terjadi heteroskedastisitas di data penelitian ini.

\section{Evaluasi Data}

Dalam evaluasi data ini peneliti akan melihat model persamaan regresi berganda dan akan menguji kebenaran hipotesis baik itu secara partial atau sendiri-sendiri, maupun secara simultan atau bersama-sama, dan untuk memudahkan peneliti dalam pengolahan data, maka digunakan Program Statistical Product and Service Solutions versi 22.00.

\subsection{Analisis Regresi Linier Berganda.}

Analisis regresi linier berganda dalam penelitian ini dapat dilihat dari persamaan regresinya, dan dari hasil pengolahan data diperoleh hasil berikut ini :

Gambar 2. Uji heteroskedastisitas

Tabel 5. Analisis regresi linier berganda

\begin{tabular}{|l|r|r|r|r|r|}
\hline \multirow{2}{*}{ Model } & \multicolumn{2}{|c|}{$\begin{array}{c}\text { Unstandardized } \\
\text { Coefficients }\end{array}$} & $\begin{array}{c}\text { Standardized } \\
\text { Coefficients } \\
\text { Beta }\end{array}$ & \multirow{2}{*}{$\mathrm{t}$} & \multirow{2}{*}{ Sig. } \\
\cline { 2 - 3 } & \multicolumn{1}{|c|}{$\mathrm{B}$} & Std. Error & & \\
\hline (Constant) & 1.034 & 6.600 & & .157 & .877 \\
\hline Budaya kerja & .523 & .119 & .531 & 4.410 & .000 \\
\hline Pemberdayaan & .214 & .095 & .260 & 2.260 & .031 \\
\hline Sikap kerja & .251 & .084 & .357 & 2.978 & .006 \\
\hline
\end{tabular}

Hasil pengolahan data, 2021

Berdasarkan Tabel 5. diatas dapat dibuat persamaan regresi dalam penelitian ini sebagai berikut:

$$
\mathrm{Y}=1.034+0.523 \mathrm{X}_{1}+0.214 \mathrm{X}_{2}+0.251 \mathrm{X}_{3}
$$

Dari persamaan regresi linier berganda di atas dapat dijelaskan :

1) Nilai kinerja pegawai di Badan Kepegawaian Daerah Kabupaten Labuhanbatu Selatan sebesar 1.034, yang mana nilai dari variabel dari variabel budaya kerja, pemberdayaan dan sikap kerja diabaikan.

2) Nilai koefisien regresi $X_{1}$ (budaya kerja) mempunyai nilai positif yaitu 0.523 , hal ini menunjukkan bahwa variabel budaya kerja mempunyai pengaruh yang searah dan positif terhadap kinerja pegawai di Badan Kepegawaian Daerah Kabupaten Labuhanbatu Selatan.

3) Nilai koefisien regresi $X_{2}$ (pemberdayaan) mempunyai nilai positif yaitu 0.214 , hal ini menunjukkan bahwa variabel pemberdayaan kerja mempunyai pengaruh yang searah dan positif terhadap kinerja pegawai di Badan Kepegawaian Daerah Kabupaten Labuhanbatu Selatan.

4) Nilai koefisien regresi $X_{3}$ (sikap kerja) mempunyai nilai positif yaitu 0.251 , hal ini menunjukkan bahwa variabel sikap kerja mempunyai pengaruh yang searah dan positif terhadap kinerja pegawai di Badan Kepegawaian Daerah Kabupaten Labuhanbatu Selatan.

\subsection{Uji Hipotesis}

\subsubsection{Pengaruh Budaya Kerja Terhadap Kinerja Pegawai di Badan Kepegawaian Daerah Kabupaten Labuhanbatu Selatan.}

Untuk mengetahui pengaruh budaya kerja terhadap kinerja pegawai di Badan Kepegawaian Daerah Kabupaten Labuhanbatu Selatan digunakan uji-t, sedangkan untuk melihat besarnya pengaruh digunakan nilai Beta atau Standardized Coefficient Beta. 
Tabel 6. Pengaruh budaya kerja terhadap kinerja

\begin{tabular}{|l|r|r|r|r|r|}
\hline \multirow{2}{*}{ Model } & \multicolumn{2}{|c|}{$\begin{array}{c}\text { Unstandardized } \\
\text { Coefficients }\end{array}$} & \multirow{2}{*}{$\begin{array}{c}\text { Standardized } \\
\text { Coefficients } \\
\text { Beta }\end{array}$} & \multirow{2}{*}{$\mathrm{t}$} & \multirow{2}{*}{ Sig. } \\
\cline { 2 - 3 } & \multicolumn{1}{|c|}{$\mathrm{B}$} & \multicolumn{1}{|c|}{ Std. Error } & & \\
\hline (Constant $)$ & 1.034 & 6.600 & & .157 & .877 \\
\hline Budaya kerja & .523 & .119 & .531 & 4.410 & .000 \\
\hline
\end{tabular}

a. Dependent Variable : Kinerja

Hasil pengolahan data, 2021

Dari Tabel 6 diatas diperoleh nilai $\mathrm{t}_{\text {hitung }}$ sebesar 4.410. Penelitian ini menggunakan taraf signifikansi $(\alpha: 0.05)$ dan Derajat Kebebasan (DK) dengan ketentuan DK $=\mathrm{n}-2$, atau $34-2$ $=32$. Dengan ketentuan tersebut, diperoleh nilai $t_{\text {tabel }}$ sebesar 2.036. Dengan kriteria hipotesis sebagai berikut :

Jika $t_{\text {hitung }}>t_{\text {tabel }}$, maka $\mathrm{H}_{0}$ ditolak dan $\mathrm{H}_{1}$ diterima.

Jika $t_{\text {hitung }}<\mathrm{t}_{\text {tabel }}$, maka $\mathrm{H}_{0}$ diterima dan $\mathrm{H}_{1}$ ditolak.

Dari hasil pengolahan data diperoleh nilai $t_{\text {hitung }}>t_{\text {tabel }}(4.410>2.036)$ dan nilai signifikasi lebih kecil dari nilai $\alpha: 0.05$ yaitu $0.000<0.05$, sehingga $\mathrm{H}_{0}$ ditolak dan $\mathrm{H}_{1}$ diterima. Artinya variabel budaya kerja secara partial berpengaruh positif dan signifikan terhadap kinerja pegawai di Badan Kepegawaian Daerah Kabupaten Labuhanbatu Selatan. Besarnya pengaruh variabel budaya kerja terhadap kinerja pegawai di Badan Kepegawaian Daerah Kabupaten Labuhanbatu Selatan sebesar 0.531 atau $53.10 \%$.

\subsubsection{Pengaruh Pemberdayaan Terhadap Kinerja Pegawai di Badan Kepegawaian Daerah Kabupaten Labuhanbatu Selatan. \\ Untuk mengetahui pengaruh pemberdayaan} terhadap kinerja pegawai di Badan Kepegawaian Daerah Kabupaten Labuhanbatu Selatan digunakan uji-t, sedangkan untuk melihat besarnya pengaruh digunakan nilai Beta atau Standardized Coefficient Beta.

Tabel 7. Pengaruh pemberdayaan terhadap kinerja

\begin{tabular}{|l|r|r|r|r|r|}
\hline \multirow{2}{*}{ Model } & \multicolumn{2}{|c|}{$\begin{array}{c}\text { Unstandardized } \\
\text { Coefficients }\end{array}$} & $\begin{array}{c}\text { Standardized } \\
\text { Coefficients } \\
\text { Beta }\end{array}$ & \multirow{2}{*}{$\mathrm{t}$} & \multirow{2}{*}{ Sig. } \\
\cline { 2 - 3 } & \multicolumn{1}{|c|}{$\mathrm{B}$} & \multicolumn{1}{|c|}{ Std. Error } & & \\
\hline (Constant $)$ & 1.034 & 6.600 & & .157 & .877 \\
\hline Pemberdayaan & .214 & .095 & .260 & 2.260 & .031 \\
\hline
\end{tabular}

a. Dependent Variable : Kinerja

Hasil pengolahan data, 2021

Dari Tabel 7 diatas diperoleh nilai $t_{\text {hitung }}$ sebesar 2.260. Penelitian ini menggunakan taraf signifikansi $(\alpha: 0.05)$ dan Derajat Kebebasan (DK) dengan ketentuan DK $=\mathrm{n}-2$, atau $34-2$ $=32$. Dengan ketentuan tersebut, diperoleh nilai $t_{\text {tabel }}$ sebesar 2.036. Dengan kriteria hipotesis sebagai berikut :

\footnotetext{
Jika $t_{\text {hitung }}>t_{\text {tabel }}$, maka $\mathrm{H}_{0}$ ditolak dan $\mathrm{H}_{1}$ diterima.

Jika $\mathrm{t}_{\text {hitung }}<\mathrm{t}_{\text {tabel }}$, maka $\mathrm{H}_{0}$ diterima dan $\mathrm{H}_{1}$ ditolak.
}

Dari hasil pengolahan data diperoleh nilai $t_{\text {hitung }}>t_{\text {tabel }}(2.60>2.036)$ dan nilai signifikasi lebih kecil dari nilai $\alpha: 0.05$ yaitu $0.031<0.05$, sehingga $\mathrm{H}_{0}$ ditolak dan $\mathrm{H}_{1}$ diterima. Artinya variabel pemberdayaan secara partial berpengaruh positif dan signifikan terhadap kinerja pegawai di Badan Kepegawaian Daerah Kabupaten Labuhanbatu Selatan. Besarnya pengaruh variabel pemberdayaan terhadap kinerja pegawai di Badan Kepegawaian Daerah Kabupaten Labuhanbatu Selatan sebesar 0.260 atau $26 \%$.

\subsubsection{Pengaruh Sikap Kerja Terhadap Kinerja Pegawai di Badan Kepegawaian Daerah Kabupaten Labuhanbatu Selatan.}

Untuk mengetahui pengaruh sikap kerja terhadap kinerja pegawai di Badan Kepegawaian Daerah Kabupaten Labuhanbatu Selatan digunakan uji-t, sedangkan untuk melihat besarnya pengaruh digunakan nilai Beta atau Standardized Coefficient Beta. 
Tabel 8. Pengaruh sikap kerja terhadap kinerja

\begin{tabular}{|l|r|r|r|r|r|}
\hline \multirow{2}{*}{ Model } & \multicolumn{2}{|c|}{$\begin{array}{c}\text { Unstandardized } \\
\text { Coefficients }\end{array}$} & $\begin{array}{c}\text { Standardized } \\
\text { Coefficients } \\
\text { Beta }\end{array}$ & \multirow{2}{*}{$\mathrm{t}$} & \multirow{2}{*}{ Sig. } \\
\cline { 2 - 3 } & \multicolumn{1}{|c|}{$\mathrm{B}$} & \multicolumn{1}{|c|}{ Std. Error } & & \\
\hline (Constant $)$ & 1.034 & 6.600 & & .157 & .877 \\
\hline Sikap kerja & .251 & .084 & .357 & 2.978 & .006 \\
\hline
\end{tabular}

a. Dependent Variable : Kinerja

Hasil pengolahan data, 2021

Dari Tabel 8 diatas diperoleh nilai $\mathrm{t}_{\text {hitung }}$ sebesar 2.978. Penelitian ini menggunakan taraf signifikansi $(\alpha: 0.05)$ dan Derajat Kebebasan (DK) dengan ketentuan DK $=\mathrm{n}-2$, atau $34-2$ $=32$. Dengan ketentuan tersebut, diperoleh nilai $t_{\text {tabel }}$ sebesar 2.036. Dengan kriteria hipotesis sebagai berikut :

Jika $t_{\text {hitung }}>t_{\text {tabel }}$, maka $\mathrm{H}_{0}$ ditolak dan $\mathrm{H}_{1}$ diterima.

Jika $t_{\text {hitung }}<\mathrm{t}_{\text {tabel }}$, maka $\mathrm{H}_{0}$ diterima dan $\mathrm{H}_{1}$ ditolak.

Dari hasil pengolahan data diperoleh nilai $t_{\text {hitung }}>t_{\text {tabel }}(2.978>2.036)$ dan nilai signifikasi lebih kecil dari nilai $\alpha: 0.05$ yaitu $0.006<0.05$, sehingga $\mathrm{H}_{0}$ ditolak dan $\mathrm{H}_{1}$ diterima. Artinya variabel sikap kerja secara partial berpengaruh positif dan signifikan terhadap kinerja pegawai di Badan Kepegawaian Daerah Kabupaten Labuhanbatu Selatan. Besarnya pengaruh variabel sikap kerja terhadap kinerja pegawai Badan Kepegawaian Daerah Kabupaten Labuhanbatu Selatan sebesar 0.357 atau $35.70 \%$.

\subsubsection{Pengaruh Budaya Kerja, Pemberdayaan dan Sikap Kerja Terhadap Kinerja Pegawai di Badan Kepegawaian Daerah Kabupaten Labuhanbatu Selatan}

Untuk mengetahui pengaruh budaya kerja, pemberdayaan dan sikap kerja terhadap kinerja pegawai Badan Kepegawaian Daerah Kabupaten Labuhanbatu Selatan digunakan ujiF.

Tabel 9. Pengaruh budaya kerja, pemberdayaan dan sikap kerja terhadap kinerja

\begin{tabular}{|l|l|r|r|r|r|c|}
\hline \multirow{2}{*}{ Model } & & $\begin{array}{c}\text { Sum of } \\
\text { Squares }\end{array}$ & \multicolumn{1}{c|}{ df } & $\begin{array}{c}\text { Mean } \\
\text { Square }\end{array}$ & \multicolumn{1}{c|}{ F } & Sig. \\
\hline \multirow{5}{*}{1} & Regression & 180.545 & 3 & 60.182 & 15.511 & $.000^{\mathrm{a}}$ \\
\cline { 2 - 7 } & Residual & 116.396 & 30 & 3.880 & & \\
\cline { 2 - 7 } & Total & 296.941 & 33 & & & \\
\hline
\end{tabular}

Dependent Variable : Kinerja

Hasil pengolahan data, 2021

Dari Tabel 9 di atas diperoleh nilai $\mathrm{F}_{\text {hitung }}$ sebesar 15.511. Penelitian ini menggunakan taraf signifikansi $(\alpha: 0.05)$ dan Derajat Kebebasan (DK) dengan ketentuan numerator : jumlah variabel -1 atau $4-1=3$, dan jumlah sampel dikurang 4 atau $34-4=30$. Dengan ketentuan tersebut, diperoleh nilai $\mathrm{F}_{\text {tabel }}$ sebesar 3.330. Dengan kriteria pengujian hipotesis sebagai berikut :

Jika $\mathrm{F}_{\text {hitung }}>\mathrm{F}_{\text {tabel }}$, maka $\mathrm{H}_{0}$ ditolak dan $\mathrm{H}_{1}$ diterima.

Jika $\mathrm{F}_{\text {hitung }}<\mathrm{F}_{\text {tabel }}$, maka $\mathrm{H}_{0}$ diterima dan $\mathrm{H}_{1}$ ditolak.

Dari hasil perhitungan diperoleh nilai $\mathrm{F}_{\text {hitung }}$ $>\mathrm{F}_{\text {tabel }}(15.511>3.330)$ dan nilai signifikasi $0.000<0.05$, sehingga $\mathrm{H}_{0}$ ditolak dan $\mathrm{H}_{1}$ diterima. Artinya variabel budaya kerja, pemberdayaan dan sikap kerja secara simultan berpengaruh positif dan signifikan terhadap kinerja pegawai di Badan Kepegawaian Daerah Kabupaten Labuhanbatu Selatan. Dengan demikian model regresi ini sudah layak dan benar dan dapat disimpulkan bahwa variabel budaya kerja, pemberdayaan dan sikap kerja berpengaruh terhadap kinerja pegawai di Badan Kepegawaian Daerah Kabupaten Labuhanbatu Selatan.

\subsection{Uji Determinan}

Uji determinan adalah untuk mengetahui seberapa besar pengaruh variabel budaya kerja, pemberdayaan dan sikap kerja terhadap kinerja pegawai Badan Kepegawaian Daerah Kabupaten Labuhanbatu Selatan, dan dapat dilihat dari model summary, khususnya nilai Rsquare. 
Tabel 10. Model summary ${ }^{\mathrm{b}}$ pengaruh budaya kerja, pemberdayaan dan sikap kerja terhadap kinerja

\begin{tabular}{|c|c|c|c|c|}
\hline Model & $\mathrm{R}$ & $R$ Square & $\begin{array}{l}\text { Adjusted } R \\
\text { Square }\end{array}$ & Std. Error of the Estimate \\
\hline 1 & $.780^{\mathrm{a}}$ & .608 & .569 & 1.96974 \\
\hline
\end{tabular}

Dependent Variable : Kinerja

Hasil pengolahan data, 2021

Besarnya Tabel 10 diatas diperoleh nilai Rsquare $\left(\mathrm{r}^{2}\right)$ sebesar 0.608 Nilai tersebut mempunyai maksud bahwa pengaruh budaya kerja, pemberdayaan dan sikap kerja terhadap kinerja pegawai di Badan Kepegawaian Daerah Kabupaten Labuhanbatu Selatan sebesar $60.80 \%$, sedangkan sisanya sebesar $39.20 \%$ dipengaruhi oleh faktor-faktor lain yang tidak diteliti. Dengan kata lain variabel kinerja pegawai di Badan Kepegawaian Daerah Kabupaten Labuhanbatu Selatan dapat diterangkan oleh variabel budaya kerja, pemberdayaan dan sikap kerja sebesar $60.80 \%$, sedangkan sisanya sebesar $39.20 \%$ disebabkan oleh variabel-variabel lain yang tidak diteliti seperti gaji, fasilitas kerja, kepemimpinan dan lain sebagainya.

\section{Pembahasan}

\subsection{Pengaruh Budaya Kerja Terhadap Kinerja Pegawai di Badan Kepegawaian Daerah Kabupaten Labuhanbatu Selatan.}

Berdasarkan pada hasil penelitian dapat dijelaskan bahwa budaya kerja berpengaruh positif dan signifikan terhadap kinerja pegawai di Badan Kepegawaian Daerah Kabupaten Labuhanbatu Selatan, hal ini didukung dengan hasil uji hipotesis yang menunjukkan bahwa nilai $t_{\text {hitung }}>t_{\text {tabel }}(4.410>2.036)$ dan nilai signifikasi lebih kecil dari nilai $\alpha: 0.05$ yaitu $0.000<0.05$. Hasil penelitian ini sejalan dengan hasil penelitian terdahulu dari Hakim (2015), dan Alia et.al (2015), keduanya menyatakan bahwa budaya kerja berpengaruh positif dan signifikan terhadap kinerja. Akan tetapi hasil penelitian bertentangan dengan hasil penelitian terdahulu dari Artina et.al (2014), yang membuat kesimpulan bahwa budaya kerja berpengaruh negatif dan tidak signifikan terhadap kinerja. Dari hasil penelitian ini dapat dijelaskan bahwa budaya kerja pegawai di Badan Kepegawaian Daerah Kabupaten Labuhanbatu Selatan secara keseluruhan pada saat ini dalam kategori baik dan dapat meningkatkan kinerja pegawai.

\subsection{Pengaruh Pemberdayaan Terhadap Kinerja Pegawai di Badan Kepegawaian Daerah Kabupaten Labuhanbatu Selatan.}

Berdasarkan pada hasil penelitian dapat dijelaskan bahwa pemberdayaan berpengaruh positif dan signifikan terhadap kinerja pegawai di Badan Kepegawaian Daerah Kabupaten Labuhanbatu Selatan, hal ini didukung dengan hasil uji hipotesis yang menunjukkan bahwa nilai $\mathrm{t}_{\text {hitung }}>\mathrm{t}_{\text {tabel }}(2.260>2.036)$ dan nilai signifikasi lebih kecil dari nilai $\alpha: 0.05$ yaitu $0.031<0.05$. Hasil penelitian ini sejalan dengan hasil penelitian terdahulu dari I Putu Magna Anuraga et.al (2017), dan Hasan Tutar et.al (2011), kesemuanya menyatakan bahwa pemberdayaan kerja berpengaruh positif dan signifikan terhadap kinerja. Akan tetapi hasil penelitian bertentangan dengan hasil penelitian terdahulu dari Arifudin et al. (2018), yang membuat kesimpulan bahwa pemberdayaan berpengaruh negatif dan tidak signifikan terhadap kinerja. Dari hasil penelitian ini dapat dijelaskan bahwa pemberdayaan yang tercipta di Badan Kepegawaian Daerah Kabupaten Labuhanbatu Selatan secara keseluruhan pada saat ini dalam kategori baik dan dapat meningkatkan kinerja pegawai.

\subsection{Pengaruh Sikap Kerja Terhadap Kinerja Pegawai di Badan Kepegawaian Daerah Kabupaten Labuhanbatu Selatan.}

Berdasarkan pada hasil penelitian dapat dijelaskan bahwa sikap kerja berpengaruh positif dan signifikan terhadap kinerja pegawai di Badan Kepegawaian Daerah Kabupaten Labuhanbatu Selatan, hal ini didukung dengan hasil uji hipotesis yang menunjukkan bahwa nilai $t_{\text {hitung }}>t_{\text {tabel }}(2.978>2.036)$ dan nilai signifikasi lebih kecil dari nilai $\alpha: 0.05$ yaitu $0.006<0.05$. Hasil penelitian ini sejalan dengan hasil penelitian terdahulu dari Chres F.P Laoh et.al (2016), Famella et.al (2015), Fonny Corryda Rahayu (2013), dan Alias et.al (2018), kesemuanya menyatakan bahwa sikap kerja berpengaruh positif dan signifikan terhadap kinerja. Akan tetapi hasil penelitian bertentangan dengan hasil penelitian terdahulu 
dari Rd. Kresna et.al (2017), yang membuat kesimpulan bahwa sikap kerja berpengaruh negatif dan tidak signifikan terhadap kinerja. Dari hasil penelitian ini dapat dijelaskan bahwa sikap kerja pegawai di Badan Kepegawaian Daerah Kabupaten Labuhanbatu Selatan secara keseluruhan pada saat ini dalam kategori baik dan dapat meningkatkan kinerja pegawai

\section{Kesimpulan}

1) Budaya kerja berpengaruh positif dan signifikan terhadap kinerja pegawai Badan Kepegawaian Daerah Kabupaten Labuhanbatu Selatan.

2) Pemberdayaan berpengaruh positif dan signifikan terhadap kinerja pegawai Badan Kepegawaian Daerah Kabupaten Labuhanbatu Selatan.

3) Sikap kerja berpengaruh positif dan signifikan terhadap kinerja pegawai Badan Kepegawaian Daerah Kabupaten Labuhanbatu Selatan.

4) Budaya kerja, pemberdayaan dan sikap kerja berpengaruh positif dan signifikan terhadap kinerja pegawai Badan Kepegawaian Daerah Kabupaten Labuhanbatu Selatan.

\section{DAFTAR PUSTAKA}

AA. Anwar Prabu Mangkunegara, (2013), Manajemen Sumber Daya Manusia Perusahaan, Remaja Rosda Karya, Bandung

Abi Sujak (2010), Kepemimpinan Manajemen, Eksistensinya Dalam Perilaku Organisasi, Rajawali Pers, Jakarta

A. Alias dan Serling Serdang (2018), Pengaruh Pengetahuan, Sikap Kerja Dan Pengalaman Kerja Terhadap Kinerja Pegawai Kantor BPJS Ketenagakerjaan Cabang Makassar, Jurnal Ilmu Ekonomi, Vol. 1 No. 1, Oktober 2018

Arifudin Aldisa, Brasit Nursin dan Dian Parawansa (2018), Pengaruh Pemberdayaan dan Budaya Organisasi Terhadap Kepuasan Kerja Serta Dampaknya Terhadap Kinerja Pegawai Dinas Perhubungan Kabupaten Merauke, Hasanuddin Journal of Applied Business and Entrepreurship, Vol 1, No. 3.

Barker, Alan (2012), Mengelola Sumber Daya Manusia, PT. Gramedia, Jakarta.

Chres F.P Laoh, Bernhard Tewal, dan Sem G Oroh (2016), Pengaruh Pengetahuan, Keterampilan dan Sikap Kerja Terhadap Kinerja Pegawai (Studi Kasus Pada PT. National Nobu Bank Area Manado). Jurnal Berkala Ilmiah, Vol 16 No. 04.
Dessler, Garry (2015), Manajemen Sumber Daya Manusia, PT. Preshelindo, Jakarta.

Dwi Sugmawati, Tri Wulida Afrianty (2018), Pengaruh Self Efficacy Terhadap In-Role Performance Pegawai Dengan Motivasi Kerja Sebagai Variabel Moderator (Studi pada Pegawai Bank Central Asia KCU Borrobudur Malang) Jurnal Administrasi Bisnis (JAB)|Vol. 61 No. 4.

Edy Sutrisno, (2012), Manajemen Sumber Daya Manusia,Kencana Pernada Media Group

Edi Suharto (2009), Membangun Masyarakat Memberdayakan Rakyat, (Bandung: PT Rafika Aditama

Fahmi, Irham (2016), Manajemen Sumber Daya Manusia, Teori dan Aplikasinya.Bandung : Alfabeta

Famella, Sri Wahyu Lelly Hana Setyanti, Ana Mufidah (2015), Pengaruh Keterampilan Kerja, Pengalaman Kerja, dan Sikap Kerja Terjadap Kinerja Pegawai Pada Perusahaan Rokok Gagak Hitam Kabupaten Bondowoso. Jurnal Universitas Jember.

Fonny Corryda Rahayu (2013), Pengaruh Sikap Kerja dan Komitmen Organisasi Terhadap Kinerja Pegawai Pada PT. Graha Agung Kencana Group Surabaya. Jurnal Universitas Pembangunan Nasional "Veteran" Jawa Timur

Ginandjar Kartasasmitha (2016), Pembangunan Untuk Rakyat: Memadukan Pertumbuhan dan Pemerataan, (Jakarta: PT Pusaka Cisendo

Gomez-Mejia, Balkin, dan Cardy, (2011), Managing Human Resources, International Edition. Prentice Hall International, Inc

Handoko (2013), Manajemen, Edisi Kedua, Cetakan Ketigabelas, BPFEYogyakarta.

Hasan Tutar, Mehmet Altinoz, Demet Cakiroglu (2011), The effect of employee empowerment on achievment motivation and the contextual performance of employees. African Journal on Business Management Vol. 5 No. 15 pp.6318-6329

Hasibuan, Malayu S.P, (2011), Manajemen Sumber Daya Manusia, Bumi Aksara, Jakarta.

Hendra, K. (2010), Pengaruh Efikasi Diri dan Motivasi Kerja Terhadap Kinerja PNS di UNIMED, Tesis, Universitas Sumatera Utara.

I Putu Magna Anuraga, Desak Ketut Sinta Asih dan I Gede Riana (2017), Pengaruh Kepemimpinan dan Pemberdayaan Terhadap Motivasi dan Kinerja Pegawai Dinas 
Pendidikan Pemuda dan Olah Raga Kabupaten Tabanandengan, E-Jurnal Ekobis Universitas Udayana 6.9 (2017) :3291-3324.

Ifa Amaliya (2018), Analisis Pengaruh Self Efficacy Terhadap Kinerja Pegawai Dengan Stres Kerja Sebagai Variabel Intervening (Studi pada Astra Isuzu Yogyakarta), http://repository.umy.ac.id/handle/12345678 9/24156.

Jatilaksono, Raditya (2016), Pengaruh Disiplin Kerja Dan Budaya Organisasi Terhadap Kinerja Pegawai CV. Abank Irenk Creative Yogyakarta. Thesis, Fakultas Ekonomi

Kasegar, R. G. (2013). Pengembangak Karir Dan Self Efficacy Terhadap Kinerja Pegawai Pada PT. Matahari Department Store Manado Town Square. Jurnal MBA, 906-916.

Mangkunegara AP, (2015), Perencanaan dan Pengembangan Sumber Daya Manusia, Rfika Aditama, Bandung

Mangkuprawira, Sjafri, (2012), Manajemen Sumber Daya Manusia. Strategik, Ghalia Indonesia,Jakarta.

Muchtar Adama (2014), Analisis Pengaruh Budaya Organisasi,Disiplin Kerja Serta Semangat Kerja Terhadap Kinerja Pegawai, (Studi Pada Kantor Dinas Pendidikan Kabupaten Sragen Bagian Subang Umum, Subag Keuangan, Subag PEP, Dikmen dan PNF Orseni, FE. UNDIP, Semarang.

Pranoto, Paulus Sugiyo. (2014). "Pengaruh Budaya Organisasi dan Motivasi Kerja terhadap Kinerja Pegawai PT. Crea Cipta Cemerlang Surabaya", Jurnal Ilmu Manajemen, Volume 2 Nomor 4.

Rd. Kresna Yudi Kusumah, Sri Suwarsi, Dudung Abdurrahman (2017), Pengaruh Kompetensi Dan Sikap Kerja Terhadap Kinerja Pegawai Di Hashi Ramen Bar Dan Resto Cimahi, SPeSIA, Prosiding Manajemen, Vol. 3, No.2.

Rizki, D. (2016). Pengaruh Self Efficacy Terhadap Kinerja Pegawai dengan Motivasi Sebagai Variabel Intervening. Jurnal Ilmu Manajemen, 4 (3).

Rivai, Veithzal dan Sagala, Ella Jauvani. (2014). Manajemen Sumber Daya Manusia Untuk Perusahaan : Dari Teori ke Praktek. Jakarta : PT. Rajagrafindo Persada

Robbins Stephen, (2015), Perilaku Organisasi, Penerbit Salemba Empat, Jakarta

Robbins, P.Stephen dan Timothy A. Judge (2012), Perilaku Organisasi. Salemba Empat. Jakarta
Rush Michel, Althoff, Phillip (2015). Pengantar Sosiologi Politik. Jakarta : PT Raja Grafindo Persada

Samsudin, Sadili. (2012). Manajemen Sumber Daya Manusia. Bandung, CV. Pustaka Setia

Santoso, Singgih (20124), SPSS Statistik Parametrik, PT. Alex Media Komputindo, Kelompok Gramedia Jakarta.

Sedarmayanti (2017), Perencanaan dan Pengembangan Sumber Daya Manusia, PT Refika Aditama, Bandung

Siagian, Sondang. (2014). Manajemen Sumber Daya Manusia (cetakan 15). Jakarta: Bumi Aksara

Sudaryono (2017), Pengantar Manajemen : Teori dan Kasus, Pernerbit CAPS, Yogyakarta

Soepardjo, Tanisa Arsya dan Nugrohoseno, Dwiarko.(2014)."Pengaruh Budaya Organisasi dan Komitmen Organisasi Terhadap Kinerja Pegawai PT. NAV Jaya Mandiri Surabaya", Jurnal Ilmu Manajemen, Volume 2 Nomor 4.

Sugiyono. (2012). Metode Penelitian Kuantitatif dan Kualitatif dan R \& D. Bandung : Alfabeta

Wulan Sari Girsang (2019), Pengaruh Budaya Organisasi dan Komitmen Terhadap Kinerja Pegawai RS Putri Hijau Medan, AJIE Asian Journal of Innovation and Entrepreneurship (e-ISSN: 2477- 0574 ; pISSN: 2477-3824) Vol. 04, Issue. 02, May 2019. 